\title{
On becoming a full partner in care
}

\author{
Cite as: CMAJ 2017 July 17;189:E943-4. doi: 10.1503/cmaj.161284
}

\section{CMAJ Podcasts: author reading at https://soundcloud.com/cmajpodcasts/161284-enc}

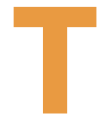

he baby book said to rock a crying infant at the same pace as a mother's heart rate: 60-100 beats/min. At that speed, it's not rocking, really; just an oscillating pressure on the ball of one foot if your legs are crossed.

But my baby son kept crying and crying. Once he cried for 37 hours in a row. His back arched and his high-pitched, catlike screams pierced the night. I rocked and quietly sang Christmas carols to the rhythm of 80 beats/min. I thought if I could just relax the muscles in my arms cradling my newborn, he might be able to settle and sleep.

But he didn't sleep, and there were other troubles, too. I couldn't persuade Nicholas' mouth into an effective suck. Why did he choke when he tried to swallow? His diaper remained dry for a whole day and the baby book said "take him to the hospital." In the emergency department, a white-haired doctor stooped to look closely at Nicholas and gently asked, "Has anyone spoken to you about your son's development?"

"No," I answered.

I thought development meant height.

A few months later, a neurologist examined Nicholas and announced, "Your son has a serious brain injury. He has cerebral palsy, mental retardation, or both. He will never be normal." My husband, Jim, and I both felt an otherworldly combination of relief (that Nick's distress wasn't due to our poor parenting), confusion and shock. I remember thinking, "If there is a diagnosis here, I can learn about it. I can beat this through the power of my love and my will." But then I realized that I knew nothing about medicine, disability or treatment. And I knew nothing about my son. He wasn't the baby I had thought he was, and in the weeks after the diagnosis, I gazed at him with an overwhelming sense of love and fear. The doctor made referrals

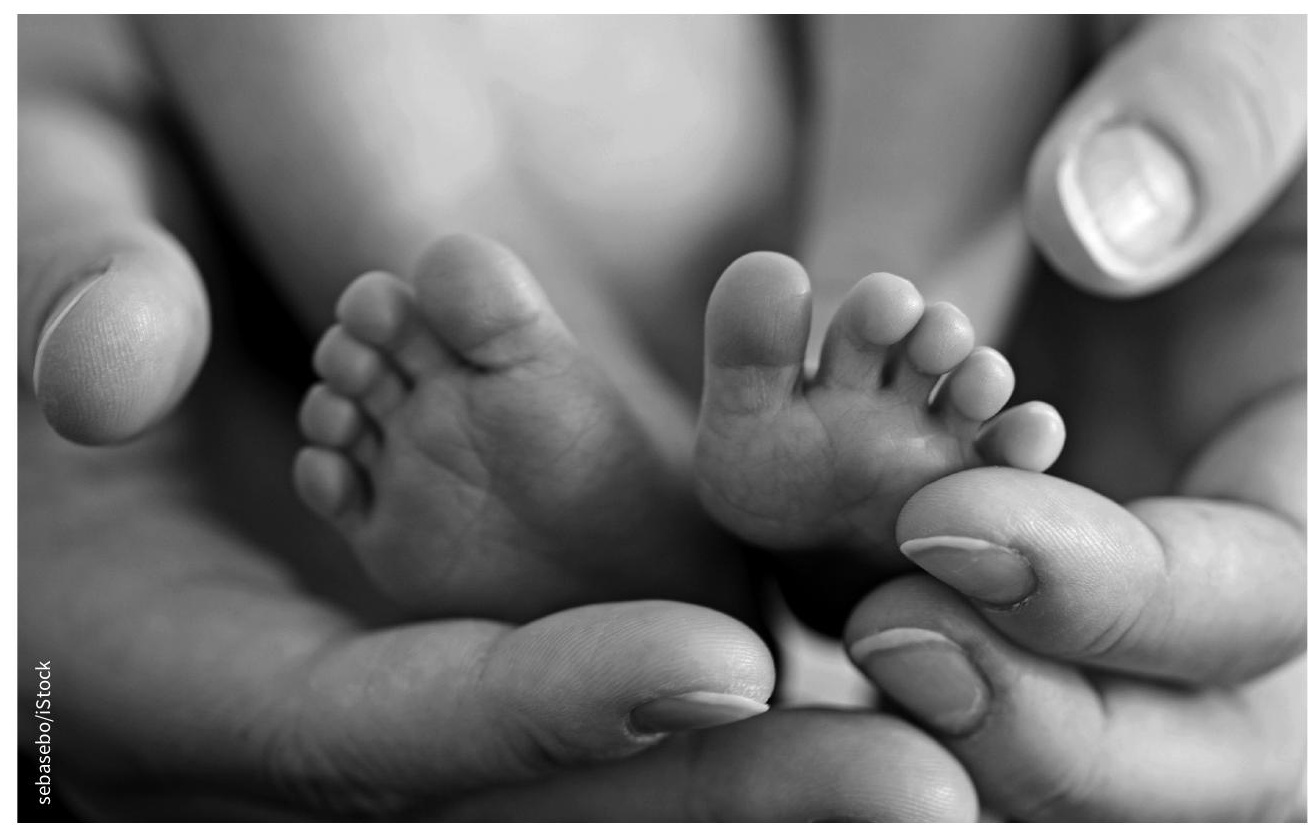

to our children's hospital and to the treatment centre.

Since Nicholas was born in 1988, he's had 9 major surgeries, 77 admissions to hospital and a lot of therapy. For 23 years, we ran a home hospital with very little help. In 2011, Nick moved into a nearby care home with 24-hour, one-to-one nursing. We are still very involved in Nicholas' life and care - we see him every couple of days and check in with his team daily.

"Are you a medical professional?" clinicians ask me. "No, just an expert in my son," I smile. But I'm an expert in how to get the best out of our health care system, too. Over the years, key members of Nick's team have come to be a kind of extended family. But as in all families, affection and dependency co-exist with shouting and slamming of doors.

I have learned that it's hard to participate as a full partner on our son's treatment team without being perceived as "difficult." My lessons in the rules of fam- ily and clinical engagement began at our first meeting with the rehabilitation team a couple of months after Nick's diagnosis. I had asked our social worker to ensure that no discussions about Nick took place without us, so I was dismayed when my husband and I arrived to discover that Nicholas' case had already been discussed. Decisions about prognosis and pre-school placement had been made and were announced to us. In this "consultation," my husband and I had one job as parents: to agree with the recommendations. I remember a feeling of dread rising in the pit of my stomach, and thinking, "We have given up our child to a system that does not see or hear us."

Around that time, medical complexity began to rear its ugly head with the diagnosis of severe gastroesophageal reflux. With innocence and optimism, we opted for an open, full-wrap fundoplication. It unleashed a storm of unremitting retching and intolerance of feeds. The traumatic postoperative 
course gave us our first glimpse of how spasms and uncontrolled pain were, for Nicholas, natural outcomes of surgery.

Then his right hip partially dislocated. A total reconstruction was performed, but two years later, it dislocated again. Pain ensued and so the final solution was deemed to be a femoral resection, which we agreed to. This was not a good decision. Spasticity caused Nick's femur to migrate upward, causing uncontrolled and unremitting pain, especially when he was sitting. We opted for multiple phenol nerve blocks, but they resulted in a painful neuralgia of Nick's right foot - an outcome we naively thought so unlikely that it hadn't been worth worrying about. An intrathecal pump running a mixture of baclofen and bupivacaine eventually gave Nick a reasonable amount of comfort in combination with strong pain meds, but bed rest was our second principal tool for pain control. Now Nick spends much of his time lying down, but he uses his positive attitude and creativity to shape a rich and busy life that he values.

Much has been made of family-centred care in developmental medicine, but I believe it's still an aspirational model that we've yet to achieve. In fact, a trend I've seen recently is parents removing their children with disabilities from therapeutic services, and even from school. Some parents are beginning to question the cost of trying to fix their child and they are bold enough to make their questions public on blogs and online parent groups. They are beginning to ask, "What does my child want to do? What do I want to do?" They say, "The price our family is paying for so little return in improved function is just too high."

In my book, The Four Walls of My Freedom, I borrowed a theory called the capability approach from Amartya Sen, a
Nobel laureate in Economic Sciences. The approach is a framework to enquire how anyone living within circumstances of adversity can be supported to have a life that they value. When I look back, Nicholas always told us what he wanted to do, and his choices were mostly the same as his able-bodied peers. But often, we weren't led by his choices. Certainly, I wasn't. Like many other parents I know, I was determined to be the best at achieving gold-star status from Nick's treatment team. My selfesteem and identity were tied to Nick reaching his developmental milestones because I believed therapy was Nick's one and only pathway to a successful future.

Throughout Nick's childhood, I don't recall any clinician asking my husband, or me, "What do you believe is happening to your son? How do you feel about your treatment choices? How can we support you now, given Nicholas' realities?" I do remember saying, "I need you to be kind to me; I really need that." In my way, I was pleading for a compassionate, honest, twoway conversation that would enable us to examine each other's understanding of where we were as a team with Nicholas' treatment and where we were likely to go. I wasn't seeking certainty; I was seeking honesty, reassurance and kindness.

So, what are the conversations families really want to have with doctors?

In the period after diagnosis, parents are in shock. We don't know what we don't know and we are frightened. I think the first question we have, which is difficult to voice, is can I love my baby? I think it's a deeply human question for parents to ask themselves, because suddenly we feel we may not have the knowledge or skills to care competently for an infant with disabilities. Soon, questions become centred on our child's future. "Will my child survive?" becomes "Will my child be happy? Will my child be able to learn at school? Will he work and have a family?" Then, later, "What will happen to my child when I die?"

Our personal histories influence the way we approach questions such as, "Should I fix my child or should I accept him as he is? What is my moral belief about the human worth and innate goodness of my child as he is?" And these are fundamental questions for cerebral palsy and developmental clinicians, too. Honest answers to those questions, shared and agreed between family and professionals, should form the foundation for a therapeutic approach. And the periodic check-up questions for families should be: "Is this approach helping our child do what he wants to do? Is the approach helping our family live the kind of life that we value, given the givens? If not, how can we change our approach?"

George Bernard Shaw said, "The single biggest problem in communication is the illusion that it has taken place." Simple, fundamental questions must be asked and answers shared so that real communication can take place between families and clinicians.

\section{Donna Thomson BFA BEd}

NeuroDevNet/Kids Brain Health Network, Toronto, Ont.

This article has been peer reviewed.

The author has spent 28 years parenting a child with severe disabilities and medical complexity. She is the author of The Four Walls of My Freedom: Lessons I've Learned From a Life of Caregiving (2010, McArthur and Co. and 2014, House of Anansi Press, Toronto) and blogs frequently at The Caregivers' Living Room (www.donnathomson.com). This essay has been adapted from the Chambers Family Lifespan Lecture, presented by the author at the American Academy for Cerebral Palsy and Developmental Medicine Annual Meeting in 2016. 